\title{
Dexamethasone serum concentrations after intravenous administration in horses during race training
}

\author{
S. McClure ${ }^{1,2}$, C. Fenger ${ }^{3 *}$, K. Kersh² ${ }^{2}$ B. Brown ${ }^{4}$, G. Maylin ${ }^{5}$, W. Duer ${ }^{6}$, L Dirikolu ${ }^{7}$, K. Brewer ${ }^{8}$, J. Machin ${ }^{9}$ and T. Tobin ${ }^{9}$ \\ ${ }^{1}$ Midwest Equine Surgery and Sports Medicine, 2615 Eastgate Drive, Boone, IA 50036, USA; ${ }^{2}$ Department of Veterinary Clinical Sciences \\ College of Veterinary Medicine, lowa State University, 1800 Christensen Drive, Ames, IA 50011-1134, USA; ${ }^{3}$ Equine Integrated Medicine,

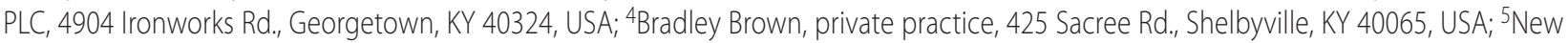 \\ York Drug Testing and Research Program, Morrisville State College, 777 Warren Rd, Ithaca, NY 14853, USA; ${ }^{6}$ Duer Forensic Toxicology LLC., \\ 1621 Gulf Blvd \#102, Clearwater, FL 33767-2928, USA; ${ }^{7}$ Department of Comparative Biomedical Sciences, School of Veterinary Medicine, \\ Louisiana State University, Skip Bertman Drive, Baton Rouge, LA 70803, USA; ${ }^{8}$ Kimberly Brewer, private practice, 15775 Cypress Creek \\ Lane, Wellington, FL 33414, USA; ${ }^{9}$ The Maxwell H. Gluck Equine Research Center, University of Kentucky, 1400 Nicholasville Rd, Lexington, \\ KY 40503, USA; drfenger@hotmail.com
}

Received: 15 February 2020 / Accepted: 16 August 2020

(C) 2020 Wageningen Academic Publishers

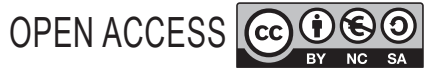

RESEARCH ARTICLE

\begin{abstract}
Dexamethasone (DXM) sodium phosphate is a widely used corticosteroid for inflammatory conditions in horses, regulated in racing jurisdictions in the USA by a $0.005 \mathrm{ng} / \mathrm{ml}$ serum/plasma threshold. This study seeks to describe serum concentrations of DXM at 48 and $72 \mathrm{~h}$ after intravenous administration of $20 \mathrm{mg}$ DXM sodium phosphate over 1 to 5 days, and to identify a possible source of DXM overages. 74 horses (39 Thoroughbreds, 13 Standardbreds, 22 Quarter Horses) in active race training received $20 \mathrm{mg}$ DXM sodium phosphate. Serum was collected before injection, at 48 and $72 \mathrm{~h}$ post last injection, and analysed by LC/MS-MS (limit of quantification (LOQ) $=2.5 \mathrm{pg} / \mathrm{ml}$ ). No differences were identified by ANOVA $(P \leq 0.05)$ for racing breeds, age, gender or the number of days of DXM sodium phosphate administration, so data were pooled for each time point. The DXM serum concentration at $48 \mathrm{~h}$ (mean \pm standard deviation, range) was $2.18 \pm 1.56 \mathrm{pg} / \mathrm{ml}(<2.5$ to $40 \mathrm{pg} / \mathrm{ml})$. Summary statistics could not be derived for $72 \mathrm{~h}$ DXM serum concentration data owing to censored data, but ranged from $<2.5$ to $95.8 \mathrm{pg} / \mathrm{ml}$. There was one extreme outlier (Tukey) at $48 \mathrm{~h}$, and two extreme outliers at $72 \mathrm{~h}$. A separate study was conducted using sedentary experimental horses to determine the likelihood that positive DXM samples could result from environmental transfer. Urine was collected from a mare 2 to $3 \mathrm{~h}$ post administration of $20 \mathrm{mg}$ DXM. Hay with $100 \mathrm{ml}$ of the DXM $(17 \mathrm{ng} / \mathrm{ml})$ containing urine was offered to each of six experimental horses and blood was collected at $0,4,8,12,16,20$ and $24 \mathrm{~h}$. All six horses had plasma DXM concentration above the limit of detection and five of six had plasma DXM concentrations above the LOQ for at least one sample time.
\end{abstract}

Keywords: horse, dexamethasone, racing, regulatory thresholds

\section{Introduction}

Dexamethasone $\left(\mathrm{C}_{22} \mathrm{H}_{29} \mathrm{FO}_{5}\right.$, molecular weight 392.461, DXM) sodium phosphate is an FDA-approved, short-acting therapeutic corticosteroid used in equine practice for the prevention and treatment of inflammatory and allergic conditions. Dexamethasone for parenteral administration can be formulated as a highly water-soluble pro-drug, DXM 21-phosphate disodium salt (Soma et al., 2013; Tobin, 1981). Following administration, the ester linked phosphate group is hydrolysed by plasma esterases (Samtani and Jusko, 2005) releasing the relatively short plasma half-life DXM (Soma et al., 2013).

Equine athletes are at risk of inflammatory airway disease (IAD), which affects up to $80 \%$ of 2 -year-old racing horses (Christley et al., 2001), resulting in impaired gas exchange and sub-optimal performance (Couëtil et al., 2016). Approximately 14\% of all age groups of racing horses suffer from IAD (Wood et al., 2005) and there is evidence that 
pulmonary inflammation contributes to the incidence of exercise-induced pulmonary haemorrhage (EIPH) (McKane and Slocombe, 2010). Because DXM has a short plasma half-life and duration of action (Soma et al., 2013), it is uniquely suited for use for treatment of IAD and other inflammatory and allergic conditions of horses approaching competition. The appropriateness of this recommendation is reflected in the Canadian Para-Mutuel Agency (CPMA) recommendation of a $48 \mathrm{~h}$ withdrawal after $25 \mathrm{mg}$ intravenous (IV), $20 \mathrm{mg}$ intramuscularly (IM), or a 5 day course of $10 \mathrm{mg}$ orally (PO) (Anonymous, 2016), and the Fédération Equestre Internationale which has a published detection time of 2 days after IV administration of $10 \mathrm{mg}$ DXM sodium phosphate (Anonymous, 2018). Similar to equine athletes, humans competing under World Anti-Doping Agency (WADA) rules cannot compete under the influence of corticosteroids. Exceptions to this rule are peri- or intraarticular corticosteroids and systemic corticosteroids when medically necessary, as determined by a Therapeutic Use Exemption (TUE), which is an application to WADA before administration. The purpose of these TUEs is to permit the administration of appropriate therapeutic medication to athletes. Corticosteroids represent the largest category of approved TUEs in human athletes since the TUE process and its predecessor program was instituted in 1986 (Fitch, 2016).

In the United States, many racing jurisdictions have adopted a regulatory threshold of $5 \mathrm{pg} / \mathrm{ml}$ DXM in plasma or serum pursuant to a recommendation by the Racing Medication and Testing Consortium (RMTC), which is accompanied by a dose recommendation of $0.05 \mathrm{mg} / \mathrm{kg}$ of DXM sodium phosphate by IV or IM administration or DXM by oral administration, and a withdrawal recommendation of $72 \mathrm{~h}$. The RMTC typically determines thresholds based on the application of a statistical method called the 95/95 tolerance (Owen, 1968), although it is not clear whether this statistical method was used in the case of DXM. The RMTC references an unpublished pharmacokinetic study in Thoroughbreds as the basis for this threshold and withdrawal (ARCI Controlled Therapeutic Medication Schedule for Horses - Version 4.1 Revised - January, 2019). Introduction of this threshold has been attendant with a large spike in racing medication overages for DXM (ARCI, 2019).

This study was undertaken in order to test the hypothesis that the RMTC-based threshold and withdrawal recommendation can be relied upon where DXM is used in fit horses in race training and to identify a possible inadvertent source of DXM overages. Specifically, we investigated the potential effect of multiple day courses of DXM sodium phosphate treatment, breed differences by including Thoroughbreds, Standardbreds and Quarter Horses under actual training conditions, and the effect on serum DXM concentration of exposure of horses to urine from a DXM sodium phosphate treated horse. We chose 48 and $72 \mathrm{~h}$ post-DXM sodium phosphate administration for collection of serum samples because most regulatory agencies use either a 48 or $72 \mathrm{~h}$ withdrawal recommendation. Further, we investigated the possibility that hay contaminated with DXM containing urine might cause random positive tests / overages for DXM.

\section{Materials and methods}

\section{Experiment 1}

\section{Study facilities and animals}

Privately owned Thoroughbred, Standardbred and Quarter Horse racehorses in race training in the practice population of two of the authors (CF, BB) were used throughout. Horses were stabled on the racetrack and were housed and trained according to standard procedures at racing facilities at Prairie Meadows Racetrack (Altoona, IA, USA) and the Red Mile (Lexington, KY, USA). The feed, bedding and water sources were consistent with routine management at each facility. Training adhered to regimens consistent with the type of racing specific to the racing discipline. Informed consent was obtained for all horses enrolled. Inclusion criteria were a full clinical examination, mucus present on endoscopy, with or without trans-tracheal cytology for a diagnosis of IAD or other inflammatory or allergic condition requiring therapy with $20 \mathrm{mg}$ DXM sodium phosphate (Bimeda, Oakbrook Terrace, IL, USA) IV. Treatment was based on the clinical examination and diagnosis by the examining investigator, a signed owner consent form, long-term trusted relationships between the investigator and trainer to ensure trainer compliance and active participation in racing or fast workouts in preparation for racing. Exclusion criteria were injections with betamethasone or DXM within 7 days, or any other medications within the $24 \mathrm{~h}$ prior to blood collection in order to minimise potential interference with the analytical method. The study was approved by the Iowa State University Animal Care and Use Committee.

\section{Experimental design}

All racehorses in two investigators' practices that fulfilled the inclusion criteria with none of the exclusion criteria were enrolled in the study. The investigators administered $20 \mathrm{mg}$ DXM sodium phosphate by IV injection, and took all precautions to prevent other exposure to DXM in the training barns. Administration of topical or oral DXM or betamethasone was restricted in the training barns. In order to replicate the usual clinical usage patterns of DXM sodium phosphate, the only restrictions on coadministered medications were the restrictions within 24 $\mathrm{h}$ of blood collection in order to prevent interference with the analytical methodology. Any concomitant medications 
were recorded. The time of day of the treatment and number of consecutive treatments were recorded. Blood samples were drawn into $10 \mathrm{ml}$ serum separator vacuum tubes immediately preceding the first dose of DXM, and at 48 and $72 \mathrm{~h}$ after the last dose of DXM. These samples were allowed to clot, then refrigerated at $2-3{ }^{\circ} \mathrm{C}$, centrifuged within $4 \mathrm{~h}$ and the serum transferred to cryovials and stored at $-70{ }^{\circ} \mathrm{C}$ for batch analysis. In seven cases where pre-injection samples were damaged such that they could not be analysed, a complete review of the horse's medical record for the last month was performed to ensure that no prior injection with any DXM or betamethasone containing product had occurred.

\section{Analytical methods}

The analytical procedure followed was the ISO 17025/ RMTC accredited quantitative analytical procedure for DXM in place in the New York Drug Testing and Research Laboratory. The analytical reference standard for DXM was purchased from Sigma Aldrich (St. Louis, MO, USA) and d4-dexamethasone (DXM-d4) from CDN Isotopes (Pointe-Claire, Canada), respectively. Stock solutions of DXM and DXM-d4 were prepared at $1 \mathrm{mg} / \mathrm{ml}$ in methanol. Acetonitrile and methanol were purchased from EMD Millipore (Sigma Millipore, St. Louis, MO, USA), and methyl tert-butyl ether and ammonium formate were purchased from Fisher Scientific (Lenexa, KS, USA). Deionised water was filtered onsite to the specification of $18.2 \mathrm{meg} \Omega$. Ethanol was purchased from Pharmco-Aaper (Brookfield, CT, USA). All reagents were of HPLC grade or better.

Working DXM solutions were prepared by dilution of the $1 \mathrm{mg} / \mathrm{ml}$ stock solution with ethanol to concentrations of 1 and $100 \mathrm{pg} / \mu \mathrm{l}$. Plasma calibrators in concentrations of $2.5,5$ and $10 \mathrm{pg} / \mathrm{ml}$ were prepared by the addition of the working standard solution to plasma harvested from experimental horses known to be drug-free. Calibration curves and negative control samples were prepared fresh for each quantitative assay.

The $2.0 \mathrm{ml}$ aliquots of samples were prepared alongside calibration curve and negative control samples. Internal standard was added to each tube. Samples were mixed by vortex, and $5 \mathrm{ml}$ of methyl tert-butyl ether was added. Samples were mixed by rotation for $10 \mathrm{~min}$, centrifuged at $2,400 \times g$ for $5 \mathrm{~min}$, the emulsion broken, and centrifuged again at $2,400 \times g$ for 5 more min. The top ether layer was removed and dried under nitrogen. Samples were dissolved in $50 \mu \mathrm{l}$ of equal parts acetonitrile, methanol, and deionised water. $2.5 \mu \mathrm{l}$ was injected into the LC-MS/MS system (Agilent Technologies, Inc, Santa Clara, CA, USA) coupled with a U/HPLC chromatography system (Agilent).
The concentration of DXM was measured in plasma by LC-MS/MS using positive electrospray ionisation with Agilent Jet Stream technology. Chromatography employed a Zorbax SB-C18 (Agilent) column with a length of $100 \mathrm{~mm}$ and a pore size of $3.0 \mu \mathrm{m}$. The beginning mobile phase composition was $50 \% 5 \mathrm{mM}$ ammonium formate in deionised water and $50 \%$ acetonitrile $(\mathrm{ACN})$. The initial ACN concentration was held at $50 \%$ for 2.75 min, ramped to $95 \%$ until $3.25 \mathrm{~min}$, and held at that concentration for until a runtime of $4.5 \mathrm{~min}$ at which the mobile phase composition was reset to the initial settings.

Detection and quantification were conducted using selective reaction monitoring (SRM) of initial precursor ion for DXM (mass-to-charge ratio $393.5 \mathrm{~m} / \mathrm{z}$ ) and the internal standard $(397.5 \mathrm{~m} / z)$. The response for the product ions for DXM $(\mathrm{m} / z 373,355,337)$ and the internal standard $(\mathrm{m} / \mathrm{z} 377)$ were plotted and peaks at the proper retention time integrated using MassHunter software (Agilent). MassHunter software was used to generate calibration curves and quantitate DXM in all samples by linear regression analysis.

The validation of the method employed for the analysis of DXM contained a calibration curve performed encompassing 2.5, 5.0 and $10.0 \mathrm{pg} / \mathrm{ml}$ DXM. The response was linear and gave correlation coefficients $\left(\mathrm{R}^{2}\right)$ of 0.99 or better. Quality control sample replicates were performed $(n=7)$. The interday accuracy was $1.9 \%$ for $5 \mathrm{pg} / \mathrm{ml}$ DXM. The intra-day accuracy was $8.3 \%$ for $5 \mathrm{pg} / \mathrm{ml} \mathrm{DXM}$. The inter-day precision was $8.4 \%$ for $100 \mathrm{pg} / \mathrm{ml}$ DXM. The intraday precision was $10.6 \%$ for $100 \mathrm{pg} / \mathrm{ml}$ DXM. The technique was optimised to provide a limit of quantitation (LOQ) of $2.5 \mathrm{pg} / \mathrm{ml}$. The limit of detection (LOD) was $1.0 \mathrm{pg} / \mathrm{ml}$.

\section{Data analysis}

The $48 \mathrm{~h}$ and $72 \mathrm{~h}$ post administration serum DXM concentrations were analysed for percentage of censored (below LOQ) data, effects of number of consecutive days of treatment using Robust Regression on Order and General Linear Model statistical methods, with statistical significance at $P<0.05$ (Helsel, 2012). The 48 and $72 \mathrm{~h}$ datasets were first analysed for percent censored data, then normality tests (Shapiro-Wilk, Anderson-Darling, Lillefors and Jarque-Bera) were performed on uncensored (above LOQ) data [using R-programming language] in order to determine the most appropriate statistical analysis for threshold determination. Where data were normally distributed, the effects of age, gender, breed and number of days treated were analysed by ANOVA [XLSTAT ${ }^{\circledR}$, ADDinsoft 2016 https://www.xlstat.com/en/ as an Excel ${ }^{\varpi}$ for Mac 2011, Microsoft add-in]. Summary statistics for each data subgroup were obtained for each group using RROS (Helsel, 2012) in R-programming language and bootstrap analyses with 100,000 resamplings [XLSTAT ${ }^{\circledR}$, ADDinsoft 2016 https://www.xlstat.com/en/ as an Excel ${ }^{\circledR}$ 
for Mac 2011, Microsoft add-in]. Bootstrap with resampling was performed to estimate population summary statistics. Thresholds for each dataset were determined using two different methods; (95/95) tolerance interval (Owen, 1968) and Gauss-Camp-Meidell (Savage, 1961) (GCM), as previously described (Machin et al., 2019). The 95/95 tolerance is calculated by:

$\mathrm{x}_{\mathrm{tol}}=\mathrm{m}+\mathrm{ks}_{\mathrm{x}}$

Where $x_{\text {tol }}$ is the $95 / 95$ tolerance threshold, $m$ is the mean and $s_{x}$ is the standard deviation of the sample population. The $\mathrm{k}$ value is a tolerance limit factor equivalent to a z-score corrected for sample size (Owen, 1968). The GCM is a probability inequality that provides bounds for the probability that the plasma concentration will fall within a given $P$-value, and requires only a unimodal distribution (Savage, 1961).

\section{Experiment 2}

\section{Study facilities and animals}

Six sedentary Thoroughbreds owned by Equine Integrated Medicine, PLC (5 mares, 1 stallion, mean \pm standard deviation (SD), range $10 \pm 5$ years old, 3 to 17 years) were used in the DXM urine environmental exposure study. Horses were stabled in the research facility of Equine Integrated Medicine, PLC, and all procedures approved by its Animal Care and Use Committee (\# AAW0012015). Feed and water sources were consistent with routine management at the facility, horses were bedded on dried grass bedding, fed a $12 \%$ Complete Feed mixture, and offered a timothy, orchard grass and bluegrass mixture ad libitum. Prior to the onset of the study, the stalls were stripped, and cleaned by pressure washing and phenolic antiseptic, allowed to completely dry for a minimum of one week, and bedded with fresh grass bedding. No medications were administered within 1 month of the study, and the horses were not in proximity to any other horses during the study.

\section{Experimental design}

A mixed breed mare was administered $0.05 \mathrm{mg} / \mathrm{kg}$ DXM IV. A Foley catheter (\#J0447H, Jorgensen Laboratories, Inc, Loveland, CO, USA) was placed at the time of administration, and the bladder evacuated. The Foley catheter was left in place, and urine collected at $3 \mathrm{~h}$ post administration. The six experimental horses were stall housed and in addition to the ad libitum mixture of grass hay, $2.27 \mathrm{~kg}$ of Lucerne hay was offered which was sprinkled with $100 \mathrm{ml}$ of the DXM containing urine. Blood samples were collected from these horses at $0,1,3,6,12$, and $24 \mathrm{~h}$ and the samples were analysed as described above. Because of the expected presence of lower serum concentrations of DXM in the contamination experiment, the LCMS method was optimised for more sensitive detection of DXM by the addition of a $1.0 \mathrm{pg} / \mathrm{ml}$ standard. The LOD was $0.5 \mathrm{pg} / \mathrm{ml}$.

\section{Results}

\section{Experiment 1}

74 horses met the inclusion criteria (Thoroughbreds, $n=39$, Standardbreds $n=13$, Quarter Horses $n=22$ ). An ANOVA showed no difference between age, gender, breed or number of daily treatments, so serum concentrations of all horses were pooled for threshold determination analysis for each of the 48 and $72 \mathrm{~h}$ datasets. Three additional horses were excluded for pre-treatment DXM serum concentrations (33 pg/ml, $4.5 \mathrm{pg} / \mathrm{ml}$ and $4.0 \mathrm{pg} / \mathrm{ml}$ ) above the LOQ, despite no identifiable exclusion criteria. Although these horses were excluded, evaluation of the 48 and $72 \mathrm{~h}$ data with these horses included did not change the results.

The number of horses that received each series of consecutive daily treatments, number censored and presence of outliers is shown in Table 1. Means and standard deviations were not determined because the numbers within each group were insufficient to employ RROS. 67 horses had preinjection serum samples below the LOQ of the analytical method for DXM. Seven horses did not have pre-injection serum samples analysed, but a review of the medical history for these horses showed no previous DXM administration or exposure, so these horses were not excluded from the analysis. Of these seven horses, five had DXM serum concentrations below the LOQ at both 48 and $72 \mathrm{~h}$. One had DXM serum concentration below the LOQ at $48 \mathrm{~h}$, and $4.1 \mathrm{pg} / \mathrm{ml} \mathrm{DXM}$ serum concentration at $72 \mathrm{~h}$. One had DXM serum concentration below the LOQ at $48 \mathrm{~h}$, and $95.8 \mathrm{pg} / \mathrm{ml}$ at $72 \mathrm{~h}$. Because the $48 \mathrm{~h}$ DXM concentrations were below the LOQ for all of the horses without pre-injection serum sample analyses, they were not excluded from the analysis. Three horses had DXM concentrations above the LOQ in the pre-injection samples with no history or evidence of DXM or betamethasone exposure within the preceding 14 days. These horses were excluded from the analysis, although the 48 and $72 \mathrm{~h}$ DXM concentrations would not have affected the analysis, had they not been excluded. Two of these horses had censored DXM concentrations at both 48 and $72 \mathrm{~h}$, and the third horse had $6.4 \mathrm{pg} / \mathrm{ml}$ of DXM at $48 \mathrm{~h}$ and censored concentration at $72 \mathrm{~h}$.

Concomitant medications were administered to 54 horses, and are summarised in Table 2. The total number of horses receiving each concomitant medication was insufficient to apply any statistical methods, so these data were pooled for statistical analysis. One extreme outlier was evident in a horse that received both phenylbutazone and flunixin. 
Table 1. The number of horses receiving each group of consecutive daily treatments, number censored, and presence of outliers.

\begin{tabular}{|c|c|c|c|c|c|}
\hline \multirow[t]{2}{*}{ Number of days } & \multirow[t]{2}{*}{ Number of horses } & \multicolumn{2}{|l|}{$48 \mathrm{~h}$} & \multicolumn{2}{|l|}{$72 \mathrm{~h}$} \\
\hline & & Number censored & Outlier (pg/ml) & Number censored & Outlier (pg/ml) \\
\hline 1 & 24 & 17 & None & 19 & $95.8 \& 10$ \\
\hline 2 & 14 & 10 & None & 14 & None \\
\hline 3 & 17 & 15 & None & 16 & None \\
\hline 4 & 6 & 5 & 40.6 & 4 & None \\
\hline 5 & 13 & 7 & None & 12 & None \\
\hline
\end{tabular}

Table 2. The number of horses receiving concomitant medications, number censored, and presence of outliers.

\begin{tabular}{|c|c|c|c|c|c|}
\hline \multirow[t]{2}{*}{ Concomitant medication } & \multirow[t]{2}{*}{ Number of horses } & \multicolumn{2}{|l|}{$48 \mathrm{~h}$} & \multicolumn{2}{|l|}{$72 \mathrm{~h}$} \\
\hline & & $\begin{array}{l}\text { Number } \\
\text { censored }\end{array}$ & Outlier (pg/ml) & $\begin{array}{l}\text { Number } \\
\text { censored }\end{array}$ & Outlier $^{3}$ (pg/ml) \\
\hline Phenylbutazone & 13 & 10 & None & 11 & $95.8^{*}$ \\
\hline Flunixin & 4 & 4 & None & 3 & $95.8^{*}$ \\
\hline Ceftiofur crystalline free acid [Excede® $]^{1}$ & 1 & 1 & None & 1 & None \\
\hline Gentamicin & 10 & 9 & None & 8 & None \\
\hline Trimethoprim-sulfadiazine & 6 & 5 & None & 6 & None \\
\hline Oxytetracycline & 10 & 7 & None & 9 & None \\
\hline Acepromazine & 1 & 1 & None & 0 & None \\
\hline Dantrolene & 1 & 1 & None & 0 & None \\
\hline Polysulfated Glucosaminoglycan [Adequan $]^{2}$ & 3 & 1 & None & 2 & None \\
\hline Dimethylsulfoxide & 2 & 1 & None & 2 & None \\
\hline Neomycin-Polymixin-Bacitracin Ophthalmic ointment & 1 & 1 & None & 1 & None \\
\hline Vitamin E/Selenium & 2 & 2 & None & 2 & None \\
\hline
\end{tabular}

The serum concentrations of DXM for the $48 \mathrm{~h}$ samples are presented in Figure 1. The presence of one outlier in the $48 \mathrm{~h}$ dataset $(40.6 \mathrm{pg} / \mathrm{ml})$ and two outliers in the $72 \mathrm{~h}$ dataset (10 and $95.8 \mathrm{pg} / \mathrm{ml})$ are noted. The percent censored data (below the LOQ of $2.5 \mathrm{pg} / \mathrm{ml}$ ) for the 48 and $72 \mathrm{~h}$ datasets were 74 and $90 \%$, respectively. Normality tests (Shapiro-Wilk, Anderson-Darling, Lillefors and JarqueBera) for each dataset indicated that non-censored data (serum concentrations above the LOQ) were normally distributed.

The $48 \mathrm{~h}$ serum concentration (mean $\pm \mathrm{SD}$ ) outlier omitted) for the $48 \mathrm{~h}$ group was $2.18 \pm 1.56 \mathrm{pg} / \mathrm{ml}$. The tolerance limits or thresholds generated using $95 / 95$ or $\operatorname{GCM}(P=0.05, P=0.01)$ for the $48 \mathrm{~h}$ samples are presented in Table 3. Thresholds could not be determined for the $72 \mathrm{~h}$ data because the $90 \%$ censored data precludes the determination of a threshold from these data (Helsel, 2012). Nine of the 74 horses had measurable DXM concentrations at $72 \mathrm{~h}$. Of those nine, seven horses, including two extreme outliers, had higher DXM concentrations at 72 than $48 \mathrm{~h}$.

\section{Experiment 2}

Results of the second experiment are shown in Table 4. Three of six horses had quantifiable concentrations of DXM, five of six had DXM concentrations above the LOD, and only one horse had no detectable DXM during the $24 \mathrm{~h}$ collection period. 


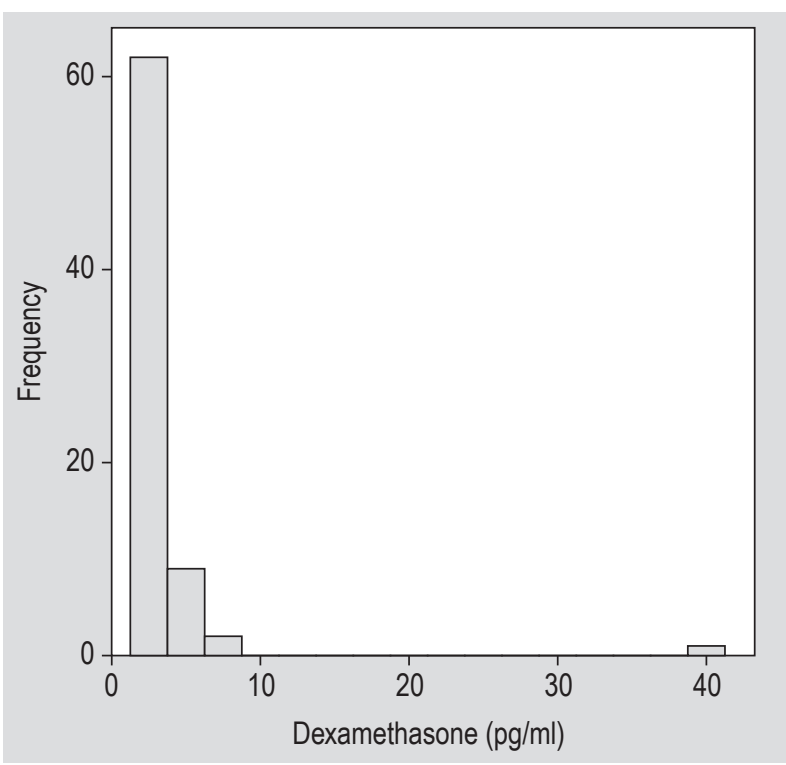

Figure 1. Frequency histogram for dexamethasone (DXM) serum concentrations $48 \mathrm{~h}$ post $1-5$ daily doses of $20 \mathrm{mg}$ DXM sodium phosphate in Thoroughbred, Standardbred and Quarter Horse racehorses in race training.

Table 3. Percent censored data, and threshold concentrations in $\mathrm{pg} / \mathrm{ml}$ as determined by $95 / 95$ tolerance, Gauss-Camp-Meidell (GCM) at $P=0.05$, corresponding to 1 in 20 risk of violating the threshold, and $P=0.01$, corresponding to a 1 in 100 risk of violating the threshold.

\begin{tabular}{lcl} 
& $\mathbf{4 8} \mathbf{h}$ & $\mathbf{7 2 ~ \mathbf { ~ }}$ \\
\% censored data points & $74 \%$ & $90 \%$ \\
$95 / 95$ tolerance & 6.61 & $\mathrm{na}^{1}$ \\
GCM $(P=0.05)$ & 6.77 & na \\
GCM $(P=0.01)$ & 12.4 & na \\
\hline${ }^{1}$ na = not applicable. & &
\end{tabular}

\section{Discussion}

This population study in racing horses was undertaken to evaluate the post DXM sodium phosphate administration serum concentrations of DXM under field conditions, and to identify possible sources of blood DXM concentrations above the regulatory threshold of $5 \mathrm{pg} / \mathrm{ml}$. No difference was found among the different racing breeds and disciplines which permitted pooling of the data for the purpose of calculating a $48 \mathrm{~h}$ threshold. Different racing breeds have previously been shown to exhibit some different pharmacokinetic parameters for glycopyrrolate (Rumpler et al., 2014), differences that may be associated with differences in study design, pharmacogenetics, or physiologic differences based on characteristics such as renal or splanchnic blood flow associated with the type of exercise. In this study, no effects of different breed or training regimes were evident for either the 48 or $72 \mathrm{~h}$ time DXM serum concentrations.

No difference was found among serum concentrations of DXM post single or multiple day treatments, indicative of no significant accumulation of DXM in horses, consistent with previous published literature. Haspel et al. (2018) found the $\mathrm{AUC}_{0-24 \mathrm{~h}}$ after a single dose to be almost identical to $\mathrm{AUC}_{0-\infty}$, indicating minimal accumulation after the conservative dose of $5 \mathrm{mg}$ used in their study. Accumulation ratios (AR) calculated from the pharmacokinetic data presented in previous studies using a low dose (AR of - 0.01 , Haspel et al., 2018) as well as a higher therapeutic dose of $0.05 \mathrm{mg} / \mathrm{kg}$ (AR of -0.002, Grady et al., 2010) fall well below an AR of 1.2, confirming the lack of accumulation (Li et al., 2012) of DXM in horses dosed at $24 \mathrm{~h}$ intervals throughout the typical therapeutic dose range. In addition to the extreme outliers, of the nine uncensored $72 \mathrm{~h}$ DXM serum concentrations, four serum concentrations exceeded the $48 \mathrm{~h}$ DXM serum concentration from the same horse, but were below $5 \mathrm{pg} / \mathrm{ml}$.

Table 4. Serum concentrations $(\mathrm{pg} / \mathrm{ml})$ of dexamethasone (DXM) detected in experimental horses after exposure to DXM containing urine contaminated lucerne hay. ${ }^{1}$

\begin{tabular}{|c|c|c|c|c|c|c|}
\hline Time after hay added (h) & Horse 1 & Horse 2 & Horse 3 & Horse 4 & Horse 5 & Horse 6 \\
\hline 0 & NDD & NDD & NDD & NDD & NDD & NDD \\
\hline 1 & NDD & NDD & $>L O D$ & NDD & $>L O D$ & NDD \\
\hline 3 & NDD & NDD & NDD & $>L O D$ & NDD & NDD \\
\hline 6 & NDD & 1.7 & 1.0 & $>\mathrm{LOD}$ & NDD & - \\
\hline 12 & NDD & $>\mathrm{LOD}$ & NDD & NDD & NDD & NDD \\
\hline 24 & 4.4 & NDD & 1.5 & NDD & NDD & NDD \\
\hline
\end{tabular}


Three samples had detectable DXM in the pre-injection samples, despite no history of DXM or other corticosteroid injection. It is possible that if the DXM sodium phosphate is withdrawn from the vial, and any bubbles in the solution are expressed from the syringe in the vicinity of the blood collection tubes, sufficient DXM can be aerosolised to cause contamination of the rubber stoppers of the collection tubes, and subsequent measurable concentrations in the blood. These samples were excluded from the analysis, but would have had no effect on the analyses, had they been included.

Three samples in our population present as extreme outliers, defined as values that exceed 1.5 interquartile ranges above the third quartile (Tukey's Outlier Test). One outlier at $48 \mathrm{~h}$ was $40.6 \mathrm{pg} / \mathrm{ml}$ and two outliers at the $72 \mathrm{~h}$ point were 10.1 and $95.8 \mathrm{pg} / \mathrm{ml}$. The horse that had the $10.1 \mathrm{pg} / \mathrm{ml} \mathrm{DXM}$ serum concentration at $72 \mathrm{~h}$ had a serum concentration at $4.4 \mathrm{pg} / \mathrm{ml}$ at $48 \mathrm{~h}$, and the horse with the $95.8 \mathrm{pg} / \mathrm{ml} \mathrm{DXM}$ serum concentration at $72 \mathrm{~h}$ had a serum concentration below the LOQ at $48 \mathrm{~h}$. While unexpected, these unusually high concentration data parallel the similar presence of high plasma concentrations in three previous pharmacokinetic papers (Soma et al., 2005, 2013; Symonds et al., 2019). At $48 \mathrm{~h}$ in Soma et al. (2005), two of six horses had plasma DXM concentrations of $600 \mathrm{pg} / \mathrm{ml}$ and $700 \mathrm{pg} / \mathrm{ml}$ after the IV administration of $0.05 \mathrm{mg} / \mathrm{kg}$, a slightly higher dose than employed in this study. In a later paper, Soma et al. (2013) reported a single outlier of 57 $\mathrm{pg} / \mathrm{ml}$ at $48 \mathrm{~h}$ among six horses after IV administration of $0.05 \mathrm{mg} / \mathrm{kg}$ DXM. While Soma did not identify this sample as an outlier, it clearly exceeds 1.5 interquartile ranges above the third quartile in his study since all of the other $48 \mathrm{~h}$ samples fell below the LOQ of the study, $10 \mathrm{pg} / \mathrm{ml}$, fulfilling Tukey's criteria as an outlier. High concentrations of DXM at $48 \mathrm{~h}$ may represent individual variability in DXM metabolism, but the study design employed in the second Soma et al. study (2013) controlled for this possibility. Soma et al. (2013) utilised a crossover design, wherein each horse was administered DXM by four different routes, intravenous, intramuscular, oral and intra-articular. Despite the multiple routes of administration, one horse exhibited the $48 \mathrm{~h} 57 \mathrm{pg} / \mathrm{ml}$ DXM plasma concentration only after IV administration and not when DXM was administered by IM or oral routes. Symonds et al. (2019) administered $0.04 \mathrm{mg} / \mathrm{kg}$ DXM sodium phosphate by nebulization, and had a single $100 \mathrm{pg} / \mathrm{ml}$ outlier at $96 \mathrm{~h}$.

An alternative explanation for the high plasma DXM concentrations in the previous Soma et al. studies (2005, 2013), as well as the $48 \mathrm{~h}$ outlier in this study would be an inadvertent subcutaneous deposition of DXM sodium phosphate at the time of the intravenous administration. Such administration would have been expected to have resulted in a sustained absorption phase, which could not be identified with our study design, but would likely have been identifiable by the pharmacokinetic parameters of the individual horses in the previous Soma studies. However, the plasma DXM outlier of $100 \mathrm{pg} / \mathrm{ml}$ at $96 \mathrm{~h}$ in the Symonds et al. (2019) study could not be explained by subcutaneous administration, because the study used a single nebulised dose of DXM sodium phosphate. The outliers at $72 \mathrm{~h}$ in our study similarly could not be explained by subcutaneous administration, because both horses were below the LOQ at $48 \mathrm{~h}$. The findings of these three previous papers and the results of our field study argue against individual metabolic variability as the source of these outliers, requiring the investigation of an alternative source of these outliers.

The horses in experiment 1 were under the control of the investigators, and received no alternative source of DXM, such as oral powders, topical creams or other compounds. As a prescription medication, DXM is only available through veterinarians, so additional unrecorded intentional administration of DXM is unlikely. However, the racetrack environment is commonly contaminated with therapeutic medications (Barker, 2008), and previous contamination of the stalls by concentrated sources of DXM, such as residual powder or compounds cannot be ruled out. Using the previously published DXM pharmacokinetics (Soma et al., 2013), our highest outlier would have only required $0.14 \mathrm{mg}$ of DXM for a blood concentration of $95.8 \mathrm{pg} / \mathrm{ml}$ at maximal blood concentration.

Alternatively, these outliers could have resulted from recycling of excreted drug. Transfer from the environment has been reported for other medications, such as flunixin (Popot et al., 2011), naproxen (Wennerlund et al., 2000) and isoxsuprine (Russell and Maynard, 2000), among others. Dexamethasone is excreted in urine in concentrations as high as $50 \mathrm{ng} / \mathrm{ml}$ after low $5 \mathrm{mg}$ dose administration (Chen et al., 1996) making concentrations as high as 200 $\mathrm{ng} / \mathrm{ml}$ likely after a dose of $20 \mathrm{mg}$, such as used in our study. Further, some of the DXM dose may be excreted in manure, such as is seen in cattle (Vanhaecke et al., 2011), leaving multiple possible routes of inadvertent ingestion from recycling of administered drug. Using the highest attained plasma concentration and bioavailability from Soma et al. (2013) rather than the average values, a volume of distribution equal to the central compartment and assuming that the $95.8 \mathrm{pg} / \mathrm{ml}$ outlier was a peak serum concentration, only $19.4 \mathrm{ml}(3.9 \mu \mathrm{g}$ DXM) of urine would need to be consumed to produce this high outlier serum DXM concentration. While this requires many assumptions, the actual bioavailability, absorption and metabolism of DXM in the horse that experienced the $95.8 \mathrm{pg} / \mathrm{ml} 72 \mathrm{~h}$ serum DXM concentration are unknown. However, DXM metabolism and disposition is highly variable (Soma et al., 2013), and could produce a relatively high serum concentrations of DXM if the urine with DXM were considered to be the source. Further, when water evaporates from urine, it becomes a concentrated source 
of salt, which may attract some horses. The horses in this field study were protected from exogenous exposure to DXM or betamethasone, and experimental horses in three previous studies (Soma et al., 2005, 2013; Symonds, 2019) experienced similar outlier plasma concentrations, indicating that such extreme outlier plasma concentrations may be a risk among horses exposed to DXM.

One of the three extreme outlier DXM serum concentrations was from a horse administered concomitant medications. This horse received both phenylbutazone and flunixin after its DXM administration. It is possible that factors related to the combination of these two non-steroidal antiinflammatory drugs contributed to the high $72 \mathrm{~h}$ DXM serum concentration. Two other horses in this study received both phenybutazone and flunixin, one of which had a $4.1 \mathrm{pg} / \mathrm{ml}$ serum DXM concentration at $72 \mathrm{~h}$, and the other which had both its 48 and $72 \mathrm{~h}$ DXM concentrations censored. No conclusions can be drawn about any possible interactions, because of the small numbers of horses that received these concomitant medications.

The second experiment was performed to investigate the possibility that DXM plasma concentrations may result from recycled urinary DXM. Table 4 shows that five of six horses offered DXM containing urine had detectable plasma DXM during at least once time point in a $24 \mathrm{~h}$ period. The highest plasma concentration was $4.4 \mathrm{pg} / \mathrm{ml}$, 24 hours after exposure to the contaminated hay, and $12 \mathrm{~h}$ after the previous plasma sampling. While this plasma DXM concentration was below the ARCI threshold of $5 \mathrm{pg} / \mathrm{ml} \mathrm{DXM}$, the peak plasma concentration could have occurred at any time in the preceding $\sim 11 \mathrm{~h}$ (Soma et al., 2013). Using the PK parameters from Soma et al. (2013), the peak plasma concentration in this horse (Horse A) could have been anywhere from $4.4 \mathrm{pg} / \mathrm{ml}$ to $24 \mathrm{pg} / \mathrm{ml}$. The DXM concentration in the urine used to contaminate hay for our experimental horses was only $17 \mathrm{ng} / \mathrm{ml}$, and we used only $100 \mathrm{ml}$ of this urine. It is clear from these data that the plasma concentrations found in our field study horses, as well as the study horses of Soma et al. (2005, 2013) and Symonds et al. (2019) could have resulted from recycled DXM from urine.

The $48 \mathrm{~h}$ serum threshold concentrations were $6.61 \mathrm{pg} / \mathrm{ml}$ using the 95/95 tolerance method, $6.77 \mathrm{pg} / \mathrm{ml}$ using GCM at $P=0.05$ and $12.4 \mathrm{pg} / \mathrm{ml}$ using GCM at $P=0.01$. The $95 / 95$ tolerance methodology provides a $95 \%$ confidence that $95 \%$ of the values will fall below the calculated threshold, where the underlying data are normally distributed (Owen, 1968). A number of assumptions are made in the calculation of 95/95 tolerance, which are previously discussed (Owen, 1968). The GCM is a probability inequality that guarantees that no more than a certain fraction of values will exceed a specified distance from the mean. The chief difference between the threshold determinations is that GCM is a distribution free method that does not require normally distributed data, only a unimodal distribution (Savage, 1961). In the case of both methods of calculating thresholds at a risk of 1 in 20, 2 of the 74 member $48 \mathrm{~h}$ data set (not including the extreme outlier), or $\approx 3 \%$ exceeded the threshold, exemplifying the point that both methods carry an approximately $5 \%$ risk of a violation where the withdrawal is carefully followed. Because the underlying assumptions for both methods of threshold determination are met, the threshold for both $95 / 95$ tolerance and GCM $(P=0.05)$ are comparable in the case of this DXM study. Where the underlying assumptions are not met, the most appropriate threshold determination methodology should be chosen (Machin et al., 2019). When the GCM methodology using a 1 in 100 risk of a positive $(P=0.01)$ is employed instead, the threshold becomes $12.40 \mathrm{pg} / \mathrm{ml}$, which exceeds all values in the dataset, other than the extreme outlier.

The statistical methods employed for threshold determination in this study for the $48 \mathrm{~h}$ dataset require several assumptions. The RROS methodology of estimating values for censored data requires that the DXM concentrations below the LOQ follow the same distribution as the measured concentrations. Therefore, the statistical moments calculated from those RROS estimates must be considered in light of these assumptions, where $72 \%$ of the data cannot be measured. However, as discussed in the preceding paragraph, this assumption is likely to be accurate, because when thresholds are calculated by two different methods that carry a $5 \%$ risk of a violation, about $3 \%$ of the population exceeds the threshold.

Statistics to determine threshold values cannot be applied where censored data exceed $80 \%$ of the dataset (Helsel, 2012). Therefore, we could not calculate thresholds by any methodology for our $72 \mathrm{~h}$ dataset. However, all but the two extreme outliers fell below the recommended $5 \mathrm{pg} / \mathrm{ml}$ threshold in place in racing in the United States. Since both horses with outlier DXM concentrations at $72 \mathrm{~h}$ were below $5 \mathrm{pg} / \mathrm{ml}$ at $48 \mathrm{~h}$, inadvertent subcutaneous drug administration or idiosyncratic metabolism are unlikely sources of these high DXM serum concentrations. Nonetheless, it is clear that a small number of horses may be at risk of exceeding the threshold at $72 \mathrm{~h}$ despite falling below the threshold at $48 \mathrm{~h}$.

The pharmacokinetic studies performed by Soma et al. $(2005,2013)$ were performed exclusively in research horses, which received no concurrent medications, and may or may not have been exercised at a level comparable to race training. Pharmacokinetics differ not only between Standardbreds and Thoroughbreds, but also between animals that are fit or sedentary (Khazaeinia et al., 2000). No previous studies have been performed to differentiate drug disposition among horses that are in Thoroughbred, Standardbred or Quarter Horse race training. 
This study provides several important guidelines for veterinarians using DXM for the treatment of IAD, other inflammatory or allergic conditions of equine athletes that perform in a regulated environment. First, this study demonstrates that there is no accumulation of DXM used at a dose of $20 \mathrm{mg} I \mathrm{~V}$ as the sodium phosphate solution once daily, so the withdrawal is the same after the final dose of intravenous DXM sodium phosphate, whether it is used for a single day or multiple days. Second, this study supports the $5 \mathrm{pg} / \mathrm{ml}$ threshold at $72 \mathrm{~h}$ with $95 \%$ confidence, because the two outlier concentrations out of 74 horses represents a $2.7 \%$ risk of a positive test. In this field study of seventyfour horses sampled at 2 time points, there were 3 extreme outliers, representing a risk of violation of approximately 1 in 50. In the Soma et al. studies $(2005,2013)$, and the Symonds study (2019), there were also extreme outliers, despite a controlled environment. Therefore, withdrawal guidelines should include warnings that there is a risk of violating the threshold, even if the withdrawal time is strictly followed. Further studies are warranted to investigate the possible sources of these outlier high serum concentrations which have presented in a number of studies.

\section{Conflict of interest}

The authors declare no conflict of interest.

\section{References}

Anonymous, 2016. Elimination guidelines 2016. Canadian Pari-Mutuel Agency, Ottawa, ON, Canada.

Anonymous, 2018. FEI list of detection times. Available at: https:// tinyurl.com/y5ncfqjc

Association of Racing Commissioners International (ARCI), 2019. Dexamethasone violations. Violations database, ARCI, Lexington, KY, USA.

Barker, S.A., 2008. Drug contamination of the equine racetrack environment: a preliminary examination. Journal of Veterinary Pharmacology and Therapeutics 31: 466-471.

Chen, C.L., Zhu, D., Gillis, K.D. and Meleka-Boules, M., 1996. Use of enzyme-linked immunosorbent assay to determine serum and urine dexamethasone concentrations in Thoroughbreds after intravenous administration of the steroid. American Journal of Veterinary Research 57: 182-186.

Christley, R.M., Hodgson, D.R., Rose, R.J., Wood, J.L., Reids, S.W., Whitear, K.G. and Hodgson, J.L., 2001. A case-control study of respiratory disease in Thoroughbred racehorses in Sydney, Australia. Equine Veterinary Journal 33: 256-264.

Couëtil, L.L., Cardwell, J.M., Gerber, V., Lavoie, J.P., Léguillette, R. and Richard, E.A., 2016. Inflammatory airway disease of horses - revised consensus statement. Journal of Veterinary Internal Medicine 30: 503-515.

Fitch, K., 2016. Glucocorticoids at the Olympic Games: state-of-the-art review. British Journal of Sports Medicine 50: 1267.
Grady, J.A., Davis, E.G. KuKanich, B. and Sherck, A.B., 2010. Pharmacokinetics and pharmacodynamics of dexamethasone after oral administration in apparently healthy horses. American Journal of Veterinary Research 71: 831-839.

Haspel, A.D., Giguere, S., Hart, K.A., Berghaus, L.J. and Davis, J.L., 2018. Bioavailability and tolerability of nebulised dexamethasone sodium phosphate in adult horses. Equine Veterinary Journal 50: 85-90.

Helsel, D.R., 2012. Robust imputation and NADA (nondetects and data analysis for R software). In: Helsel, D.R. (ed.) Statistics for censored environmental data using Minitab ${ }^{\oplus}$ and R, $2^{\text {nd }}$ edition. Wiley and Sons, Hoboken, NJ, USA, pp. 79-98 and 297-302.

Khazaeinia, T., Ramsey, A.A. and Tam, Y.K., 2000. The effects of exercise on the pharmacokinetics of drugs. Journal of Pharmacy and Pharmaceutical Sciences 3: 292-302.

Li, L., Li, X., Xu, L., Sheng, Y., Huang, J. and Zheng, Q., 2013. Systematic evaluation of dose accumulation studies in clinical pharmacokinetics. Current Drug Metabolism 14: 605-615.

Machin, J., Duer, W.C., Maylin, G.A., Fenger, C.K., Wilson, D., Ivey, M., Berthold, B., Allison, S. and Tobin, T., 2019. Variability in plasma concentrations of methylprednisolone six days after intra-synovial injection of methylprednisolone acetate as depo-medrol in racing horses: a field study. Equine Veterinary Journal 51: 343-348.

McKane, S.A. and Slocombe, R.F., 2010. Experimental mild pulmonary inflammation promotes the development of exercise-induced pulmonary haemorrhage. Equine Veterinary Journal 42, Suppl. 38: 235-239.

Owen, D.B., 1968. A survey of properties and applications of the noncentrally t-distribution. Technometrics 10: 445-478.

Popot, M.A., Garcia, P. and Bonnaire, Y., 2011. Doping control in horses: housing conditions and oral recycling of flunixin by ingestion of contaminated straw. Journal of Veterinary Pharmacology and Therapeutics 34: 612-614.

Rumpler, M.J., Colahan, P. and Sams, R.A., 2014. The pharmacokinetics of glycopyrrolate in Standardbred horses. Journal of Veterinary Pharmacology and Therapeutics 37: 260-268.

Russell, C.S. and Maynard, S., 2000. Environmental contamination with isoxsuprine. In: Williams, R.B., Houghton, E. and Wade, J.F. (eds.) Proceedings of the $13^{\text {th }}$ International Conference of Racing Analysts and Veterinarians, Cambridge. R\&W Publications, Newmarket, UK, p. 383.

Samtani M.N. and Jusko, W.J., 2005. Stability of dexamethasone sodium phosphate in rat plasma. International Journal of Pharmaceutics 301: 262-266.

Savage, R., 1961. Probability inequalities of the Tchebycheff (Chebyshev) type. Journal of Research of the National Bureau of Standards, Section B: 65B: 211-222.

Soma, L.R., Uboh, C.E., Liu, Y., Li, X., Robinson, M.A., Boston, R.C. and Colahan, P.T., 2012. Pharmacokinetics of dexamethasone following intra-articular, intravenous, intramuscular, and oral administration in horses and its effects on endogenous hydrocortisone. Journal of Veterinary Pharmacology and Therapeutics 36: 181-191. 


\section{S. McClure et al.}

Soma, L.R., Uboh, C.E., Luo, Y., Guan, F., Moate, P.J. and Boston, R.C., 2005. Pharmacokinetics of dexamethasone with pharmacokinetic/ pharmacodynamic model of the effect of dexamethasone on endogenous hydrocortisone and cortisone in the horse. Journal of Veterinary Pharmacology and Therapeutics 28: 71-80.

Symonds, N.E., Dart, A.J., Keledjian, J., Liu Lau, M., Ennis, L.C., McIver, V.C., Tsang, A.S., Biasutti, S.A. and Jeffcott, L.B., 2019. Pilot study to quantify the time to clear dexamethasone from plasma and urine of adult horses following a single nebulization. Australian Veterinary Journal 97: 144-148.

Tobin, T., 1981. Drugs and the performance horse. Charles C. Thomas, Springfield, IL, USA, pp. 480.
Vanhaecke, L., Antignac, J.P., Courtheyn, D., Le Bizec, B. and De Brabandera, H., 2011. Elimination kinetics of dexamethasone in bovine urine, hair and feces following single administration of dexamethasone acetate and phosphate esters. Steroids 76: 111-117.

Wennerlund, I., Invast-Larrson, C., Kallings, P., Fredrickson, E. and Bondesson, U., 2000. Pharmacokinetics and urinary excretion of naproxen after repeated oral administration in the horse. In: Williams, R.B., Houghton, E. and Wade, J.F. (eds.) Proceedings of the $13^{\text {th }}$ International Conference of Racing Analysts and Veterinarians, Cambridge. R\&W Publications, Newmarket, UK, pp. 377-380.

Wood, J.L., Newton, J.R., Chanter, N. and Mumford, J.A., 2005. Association between respiratory disease and bacterial and viral infections in British racehorses. Journal of Clinical Microbiology 43: $120-126$. 